\title{
Atmospheric Pollution and Urban Development in China
}

Benjamin Guinot

\section{(2) OpenEdition \\ Journals}

Electronic version

URL: http://journals.openedition.org/chinaperspectives/4741

DOI: 10.4000/chinaperspectives.4741

ISSN: 1996-4617

Publisher

Centre d'étude français sur la Chine contemporaine

\section{Printed version}

Date of publication: 1 December 2008

Number of pages: 63-70

ISSN: 2070-3449

\section{Electronic reference}

Benjamin Guinot, «Atmospheric Pollution and Urban Development in China », China Perspectives

[Online], 2008/4 | 2008, Online since 01 December 2011, connection on 28 October 2019. URL : http:// journals.openedition.org/chinaperspectives/4741 ; DOI : 10.4000/chinaperspectives.4741 


\title{
Atmospheric Pollution and
}

\section{Urban Development in China}

\author{
BENIAMIN GUINOT
}

Chinese cities face the challenge of battling air pollution during a time of rapid urbanisation and rising energy demand. Poor air quality is heightening anxiety over the environment. Given pollution's economic cost, a real policy of monitoring and control has emerged at the national level. Chinese researchers and industry have come up with technological responses to the enormous challenges. While some showcase cities have boosted their pollution-control measures, the situation in smaller ones remains largely catastrophic.

$\mathrm{C}$ hinese cities' absorption of millions of new residents is unprecedented in modern world history. The extent of this rural exodus is especially noticeable in the periphery of provincial capitals or sub-prefectures along coastal regions, with whole new localities rising up overnight. While in the late 1980s urban residents represented a mere 10 percent of China's population, they have exceeded 40 percent during the current decade and could rise to 60 percent by 2020. China could account for a third of the two-fold rise in the world's urban population between 1990 and 2025. This urbanisation is seen as a chance for Chinese people to acquire modernity and a more comfortable life still inaccessible in the countryside or small towns. But the process is so rapid and of such magnitude that there is little control. There is thus great pressure on natural resources needed for the functioning of these expanding urban zones. Firstly, water, the reserves of which are limited in many regions, ${ }^{(1)}$ is often distributed through inadequate networks. At the other end of the chain, drainage networks are unable to cope with the speed of construction and the newly generated quantities of liquid waste. Secondly, rapidly growing energy use in industry and homes in urban centres generates dense air pollution with worrying environmental impact on both a national and global scale. Chinese cities are thus a window on the future, where problems but also many possible solutions related to sustainable development and energy policy could emerge within a short period.

The authorities confront the pressing challenges of reducing pollution in the atmosphere and supporting the standard of living and energy use of the urban population. Chinese actions in meeting these challenges differ, however, from those of developed countries due to the as yet low level of urbanisation. This will in coming years lead to the interaction of two new variables. Firstly, the growth rate of existing major urban centres is expected to rise sharply, as happened in the United States and other developed countries when urbanisation crossed 30 percent. Then there is the rate at which populations are exposed to health risks from pollution: while the populations of developed countries had become largely urban by the time they experienced their periods of highest pollution in the 1970s and 1980s (74 percent of US citizens in 1970, for example), China's population is still in the throes of socio-economic upheaval, meaning that the government's varied and changing policies to limit pollution are difficult to implement.

This article looks at the complexity of the problem, tracing its evolution from the 1980s and the rise in urban economic standards. The evolution of central and local authorities' responses is then recounted, followed by an examination of atmospheric pollution control in China through the perspective of Beijing's experience.

\section{The nature of pollution evolves with a city's level of develop- ment}

The 2007 Report on the State of the Environment ${ }^{(2)}$ noted that nearly 40 percent of cities with air quality monitoring

1. Northern regions ( $1 / 3$ of GDP, 42 percent of population) face rising and sustained desertification according to regional climatic projections (see the freely accessible Regional Climate of China, Springer Berlin Heidelberg Ed., 2008: http://www. springerlink.com/content/978-3-540-79241-3). 
networks ${ }^{(3)}$ reported pollution indices equal to or greater than the maximum level, Category 3 , the threshold values of which are in fact five times higher than WHO limits. ${ }^{(4)} \mathrm{An}-$ other third were only marginally better off, meaning that three-fourths of China's urban residents breathe noxious air. The highest pollution is in urban areas with one to eight million inhabitants. These are mostly provincial capitals or coastal cities where economic development depends on heavy industry, especially those engaged in energy, metallurgy, and chemicals. Traditionally these cities have suffered from pollution linked to burning coal, China's top energy resource. Local authorities lack the human, financial, and technological means needed to deal with such pollution, unlike big and rapidly modernising cities such as Beijing, Shanghai, Tianjin, Shenzhen, or Guangzhou. These megacities are undergoing a radical restructuring of industrial activity, which is disappearing from city centres either to be reestablished farther away in more modern settings or yielding place to high-value-added industrial or tertiary activities. Moreover, in these cities, residences eschew coal (for heating and cooking) in favour of gas or electricity. All these changes have contributed greatly to reducing atmospheric pollution. But the corollary to this modernisation is the rise in traffic pollution: the atmosphere in these "modern" cities thus resembles that of developed countries more and more.

\section{Evolution of pollution, from $\mathrm{SO}_{2}$ to suspended particles}

Atmospheric pollution in China has long been closely associated with sulphur dioxide $\left(\mathrm{SO}_{2}\right)$ produced in the burning of coal, the major content of which is sulphur. In the 1990s, several measures targeting the industrial sector helped contain the effects of rising coal use (up 50 percent between 1990 and 2005) on air quality. This was done mainly by inducing industries to use better quality coal, that is, with less sulphur content. As a result, $\mathrm{SO}_{2}$ concentration in the atmosphere fell by 50 percent during this period. However, the issue of $\mathrm{SO}_{2}$ emissions has not been resolved yet, as a third of China's territory is exposed to acid rain caused mainly by the burning of coal.

Desulphurisation systems installed to trap $\mathrm{SO}_{2}$ from industrial waste are often cited as the technological solution to the problem. In reality, only a few industrial units have installed them in China. These high technology systems are costly to use, and in practice operate only during inspections. It is thus not surprising that China has failed to attain its aim of reducing $\mathrm{SO}_{2}$ emissions over the last three years. ${ }^{(5)}$ It is worth recalling that cities in Europe, the United States, and Japan for which data is available experienced similar pollution levels in the 1970-1980 period, in fact even higher than those recorded in China now. Thus, in this decade, the average values of $\mathrm{SO}_{2}$ in industrial cities such as Lanzhou, Taiyuan, Shenyang, and Chongqing, are comparable to those observed in the 1980s in Seoul and in major European industrialised countries such as Belgium or the Netherlands. ${ }^{(6)}$

It was only in the early 1990s that environmental authorities perceived atmospheric pollution and began to tackle the problem of suspended particles in the air. Until then, observers regularly recorded the visibility (measured in kilometres) in most cities ${ }^{(7)}$ without linking it to variations in the concentrations of particles (also called aerosols), which was what mattered. Archives from that period show a remarkable correlations between atmospheric visibility and energy consumption data ${ }^{(8)}$ thus illustrating that Guangdong Province and the Pearl River Delta comprised the first region in the country to suffer severe episodes of particle pollution in the mid-1980s.

The concentrations of these particles were first reported in terms of Total Suspended Particles (TSP), which have largely exceeded China's own standards, especially in cities in the north, where coal is intensively used in heating and where paltry rain and massive soil erosion leads to large quantities of mineral dust remaining suspended. For instance, the average national value was around $400 \mu \mathrm{g} / \mathrm{m}^{3}$ in the late1980s and had only fallen by a third ten years later. TSP levels did not fall from 1999 until 2003, ${ }^{(9)}$ despite a historic reduction in energy consumption between 1997

2. RSEC 2007, Report on the State of the Environment in China, China State Environmental Protection Administration, Beijing. http://www.mep.gov.cn/plan/zkgb/2007zkgb/ 200811/t20081117_131297.htm.

3. 113 cities were covered by the central policy of developing monitoring networks set up in the 11th plan. For details see http://www.gov.cn/zwgk/2007-11/26/content_815498.htm.

4. World Health Organisation.

5. RSEC, 2007, ibid.

6. Thomas G. Rawski, "Urban air quality in China: Historical and comparative perspectives," in Resurgent China: Issue for the future, Nazrul Islam ed., Palgrave-Macmillan, 2008, accessible via the website of University of Pittsburgh, Department of Economics, Working Paper No. 282, http://ideas.repec.org/s/pit/wpaper.html.

7. Qiu Jinhuan et al, "Variation characteristics of atmospheric aerosol optical depths and visibility in North China during 1980-1994," Atmospheric Environment, №. 34, 2000, pp. 603-609. See also: Wu Dui et al, "Effect of atmospheric haze on the deterioration of visibility over the Pearl River Delta," Acta Meteorological Sinica, No. 64, 2006, pp. 510-517.

8. David G. Streets, "Did aerosols over China peak in the 1990s?" 2007, http://www.gee21.org/publications/ DiscussionPapersand JournalPublications.html.

9. Jonathan E. Sinton et al, «An assessment of programs to promote improved household stoves in China," Energy for Sustainable Development, No. 8, 2004, pp. 33-52. 
Figure 1. Nitrogen dioxide (NO2) concentrations in China's atmosphere in (November 2007 October 2008). Data from SCIAMACHY, the spectrometre aboard ESA's satellite, ENVISAT.

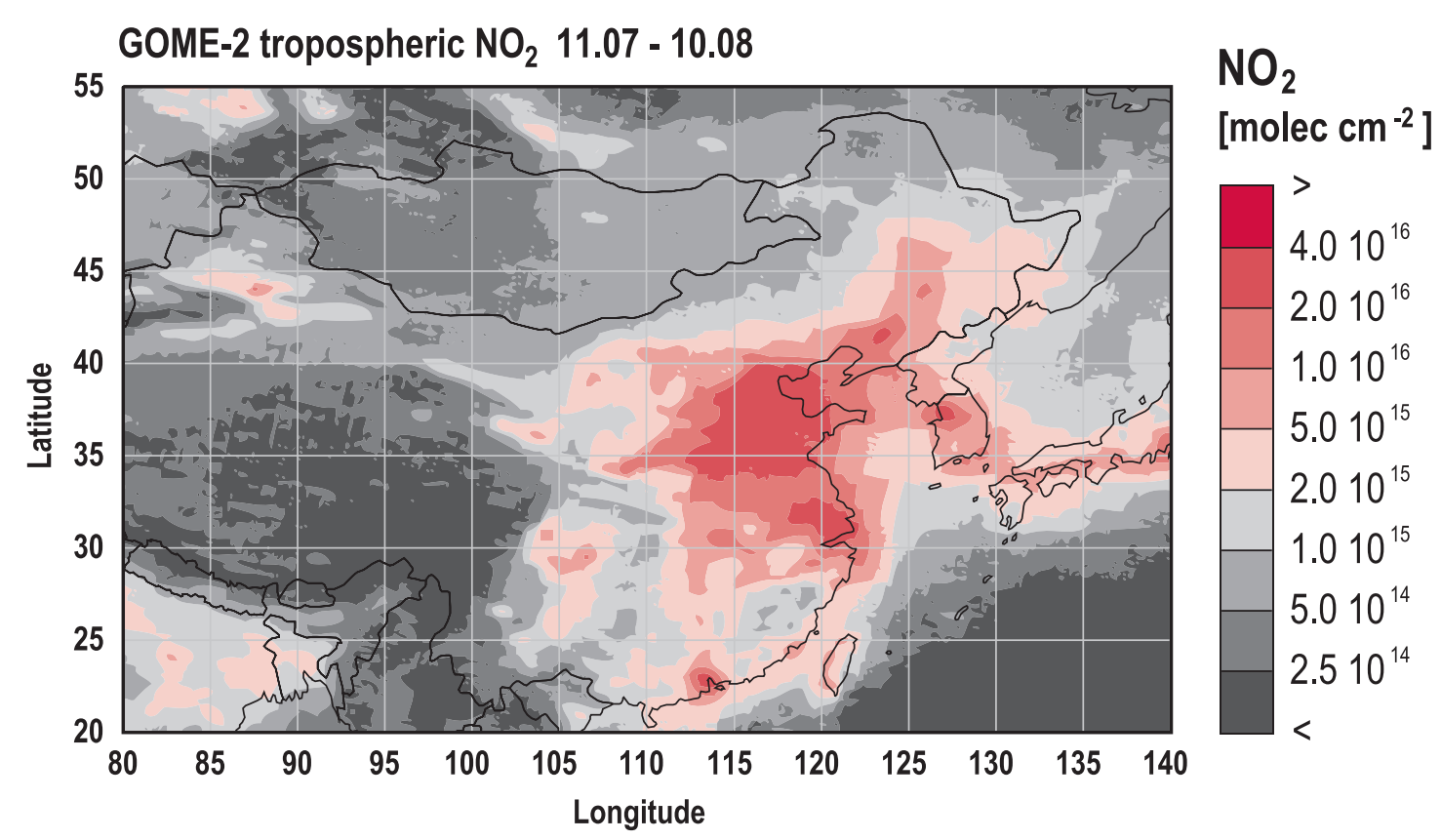

and 2002. With a view to adopting international standards, the yardstick was changed in 1996 from TSP to $\mathrm{PM}_{10}$, the latter standing for particles with diameters of less than $10 \mathrm{mi}-$ crons. This yardstick thus ignored the biggest atmospheric particles. From 2000, PM 10 data were available in cities with monitoring networks. Since then, despite efforts at controlling industrial pollution sources and the gradual replacement of coal with natural gas in newer urban residences, the fall in $\mathrm{PM}_{10}$ levels in the China's largest 100 cities has been irregular and unimpressive, of the order of 10 percent. ${ }^{(10)}$ Today, particulate concentrations are five to eight times higher than in Western Europe or the United States, particulate matter being the main source of urban pollution in China.

While concentrations of $\mathrm{SO}_{2}$ and of TSP/PM 10 have been regulated, though not significantly reduced, this has not been the case with nitrogen oxides ( $\mathrm{NOx}$ ), including $\mathrm{NO}$ and $\mathrm{NO}_{2}$, nor with fine particles (which can be breathed in). Their levels have continued to rise due to the explosive increase in automobiles (at 20 percent annually since 1996) and in energy consumption (up 50 percent between 1990 and 2005). This general increase since 1996 can be directly linked to the economic development of urban areas. It happened firstly in southern cities such as Guangzhou, which registered growth rates significantly higher than those in the north before megacities such as Beijing, Tianjin, and Shanghai caught up with the trend of contributing their share of pollution, as shown in Figure 1. In these megacities, nitrogen oxides, with their role as precursors of ozone and other secondary pollutants and particulates, represent a priority issue for air quality, of the same magnitude as suspended particles.

\section{The evolution of environmental governance}

Chinese authorities had included the environmental issue in their agenda early on, but without really addressing the problem. In 1974, when the State Environmental Protection Administration (SEPA) was set up, the key word for various levels of the executive was "productivity" and remained so for the next two decades. It was only in the 1990s, when China began flexing its muscles internationally, that basic changes were initiated. The Beijing Olympics of 2008 and Expo 2010 in Shanghai without doubt helped to accelerate the application of ambitious rules on air quality, but had no real influence outside the major cities. Rather, it was the economic cost of development through its effect on environ-

10. RSEC, 2007, Ibid. 
ment and health that caused the government to revise its priorities. However, this rebalancing in favour of environmental protection has been slow, with many obstacles impeding progress. A World Bank study estimated the damage caused to the environment in China in 2003 at 3.8 percent of GDP. Recent projections ${ }^{(I I)}$ show that current pollution control policies, deemed too lax, would not prevent a doubling of this level of damage in the 20 years to come, given the galloping urbanisation and rising standard of living of urban residents.

The slowly changing priorities of state leaders took on concrete form in March 2008, when SEPA was elevated to ministerial rank (Ministry of Environmental Protection, MEP). As a central authority with enhanced powers, MEP received as its first assignment the rehabilitation of the environment according to the aims defined in the 11th Five Year Plan (2006-2010). While reviewing this recent history, it is interesting to bear in mind that in the United States the US-EPA (Environmental Protection Agency) was only created in 1970 when per capita income was $\$ 21,000$ (at 2005 value), whereas SEPA in 2005 attained a comparable level of technological expertise while China's per capita income stood at no more than $\$ 4,100$. It is therefore worth underlining that the Middle Kingdom became a notable exception to the famous Environmental Kuznets Curve, which charts a relationship between per capita income and the level of environmental pollution. The inverted $U$ of Simon Kuznets is translated as the "pollute first, improve later" pattern that Western powers followed. In China, the problem of limited resources - energy, water, and air - preoccupies the government as never before in a global context of unprecedented levels of environmental concern. Moreover, the term "scientific development" was introduced in the Communist Party dialectics during its 17th National Congress in October 2007. China knows that an unchecked appetite for natural resources would keep it from attaining the second, so-called "green" phase of development and imperil the nation's economic and social harmony. This implies adoption of new paths to development, in which energy efficiency and control of pollution sources take pride of place. ${ }^{(12)}$

\section{Does industry retard or boost the growth of environmental governance?}

In the atmospheric pollution domain, MEP chose to work closely with industry for two reasons. The first is that industry consumes 71 percent of primary energy sources in China and 94 percent of its coal, ${ }^{(1)}$ so controlling industrial emissions serves to act against the leading cause of atmospheric pollution in China. Also, use of the industrial lever helps harness economic dynamism and address internal constraints. Thus in late 2007, SEPA launched a new and innovative policy of "green credits" in partnership with the Bank of China and the China Banking Regulatory Commission, which aimed to tie a company's eligibility for bank loans to its environmental performance. More recently, two other measures were announced, requiring that enterprises in the most polluting sectors (energy, metals, and cement) take out pollution insurance policies, and compelling firms seeking to list on the stock market or issue new shares to submit to pollution control measures.

Overall, the effect of these measures was minimal or hardly noticeable in some industries and even counter-productive in others, mainly because few banks had their own independent environmental policies. ${ }^{(14)}$ As for improving industrial management, while it is necessary for better regulation of emissions, a recent study has shown that augmenting the capacity of industrial units to improve environmental protection does not lead to less polluting waste but rather to an increase of 0.59 points. ${ }^{(15)}$

Meanwhile, 13 years after the adoption of the first standards on air quality, the capacity of environmental authorities (MEP and the Environmental Protection Bureau, EPB) to ensure implementation and observance remains limited. Of course, the recurring problem that faced the former SEPA in ensuring application of national rules at the local level also dogs the MEP, which meanwhile has to seek better coordination with EPB branches across China. Depending on the political weight of the local governments that finance them, and on their willingness to take up environmental concerns, there is great disparity among EPB branches when it comes to monitoring and checking atmospheric pollution. Again, the major urban centres stand out, serving as laboratories and windows and heightening the country's environmental

11. Mun S. Ho and Dale W. Jorgenson, "Greening China: Market-based policies for air-pollution control," Harvard Magazine, September 2008, http://harvardmagazine.com/ 2008/09/greening-china.html

12. In linking atmospheric pollution indicators and the leading role of labour in the active population, Thomas Rawski (see footnote 6) showed that the diminution in the levels of particles and S02 started at a lower level of development compared to that of the United States, Japan, and South Korea.

13. China Statistical Yearbook 2006, 2007. China National Bureau of Statistics, Beijing, China Statistics Press.

14. HEC Eurasia Institute, March 2008 (http://www.hec.fr/eurasia).

15. Li Wanxin et al, "Translating Regulatory Promise Into Environmental Progress: Institutional Capacity and Environmental Regulation in China," ELR, No. 36, 2006, pp. 1061610623. 
consciousness. With economic growth in the double digits, and the ability to project an international image on the strength of international events, some cities have the means to see that their rapid transformation is accompanied by radical restructuring as well. Albeit still weak, this tendency can be seen in industrial cities such as Tianjin and Shenzhen, and in the most dynamic coastal cities. But in the capitals of central provinces or smaller cities of under a million residents, enforcement by EPB branches remains largely ineffective. Their capacity should not be gauged by the volume of instruments at their disposal, but rather by the quality of technical monitoring work and the level of scientific and technical cooperation they have established with major national and international universities. It has been shown that in China human capital is a more powerful lever than financial investment in ensuring respect for standards. ${ }^{(16)}$

\section{Defining adapted standards for air quality}

Defining standards for ambient air quality depends first of all on scientific knowledge regarding the sources of pollutants and their evolution, as well as their effects on health. When in 1996 China launched campaigns to test air quality in the most developed cities, the specifics of atmospheric pollution had not been determined to a degree where SEPA could target pollutants and properly define tolerance levels, and the authorities had to rely on standards established in the United States, Japan, and Europe. However, they did not neglect the acquisition of measurement technologies by the agencies in leading cities and by national scientific and technical institutions, or the training of engineers to master them. Today, nearly 200 cities have air quality monitoring stations, and 86 of them issue daily reports of indices for various pollutants ${ }^{(17)}$ as published by the MEP.

The first wave of acquisition of air quality measurement networks in the late 1990s largely benefited foreign companies dealing in such instruments. The leaders among them were Thermoelectron and Teledyne API (United States), as well as Environnement SA (France). These three firms today share about 70 percent of the market in the most developed cities. Medium ranking cities were equipped more recently (2005-2008), but as it happened when conditions were unfavourable for European imports, instruments of middling quality were acquired largely from within China. In a related area, that of vehicle exhaust, a lobby of countries producing monitoring equipment was able to dictate the standards, benefiting mostly European, Japanese, and Korean manufactur- ers to the detriment of the Americans. Chinese producers followed later.

Goaded by market dynamics, Chinese R\&D strategy from the start of this decade was resolutely oriented towards the production of atmospheric pollution measuring instruments. Industrial enterprises making and marketing them were offshoots of research groups linked to the Chinese Academy of Sciences or major universities. More recently, the capacity for technological innovation within some Chinese institutes has helped them compete with larger foreign firms in the manufacture of conventional instrumentation for monitoring air quality, and their market share has increased. Thus nearly all Chinese research-enterprise partnerships currently favour the adaptation of new measurement techniques, such as DOAS (Differential Optical Absorption Spectrometry) measurement, which have a strong potential to address China's various urban atmosphere problems. In encouraging such new technologies to play a key role in its pool of atmospheric pollution monitoring devices, China hopes to position itself as a leader in a segment neglected by foreign enterprises. The country is thus readying itself to influence the choice of technologies that will be used in Asia and rest of the world further down the line.

Meanwhile, basic research has not been neglected, as Chinese scientists have been contacting and catching up with the best researchers in the field. Since the first international collaborations in 1978, and more significantly since the mid 1980s, hundreds of articles have been published in specialised journals. The quality of these contributions stems from research as sophisticated as that in Europe, and applied in a more complex environment. The progress made in recent years is largely due to research collaborations carried out in China itself. This is especially the case in the field of particulate pollution, where there are still many unknowns in China given the multiplicity of sources, climatic conditions, and popular habits throughout the country. In order to evaluate the health and radiation impacts, monitoring of particulates has graduated from measuring them together (TSP) to examining the most active classes of particulates, that is to say the tiniest ones $\left(\mathrm{PM}_{10}, \mathrm{PM}_{2.5}, \mathrm{PM}_{1}\right.$, or particulates measuring less than $10,2.5$ or 1 micron in diameter). It is thus clear that these basic research efforts combined with the technological advances examined earlier provide China with

16. Ibid.

17. The Air Pollution Index (API) in China is calculated for each of the following: PM10, S02, N02. Only the highest of the three values is retained for reporting purpose. Unlike European and American indices (often called the Air Quality Index or AQI rather than API), the Chinese index does not take all pollutants into account, and ozone is not considered. 
the capacity to set its own standards - that is to say, to shed the influence of developed countries while emerging as a reference point for developing countries close by.

\section{Future perspectives: The case of} Beijing

Those who lived in Beijing in the 1970s recall with nostalgia and a certain incredulity that they used to boast of a sky bluer than that of any other city in China. The demography at that time posed no constraints on the municipality, which was organised in districts with communities of workers living close to their jobs. Large-scale industrialisation and reforms upset this scenario in the early 1980s. Factories were moved to the countryside on the outskirts of the city, which was given the room needed to develop its suburbs. Since then Beijing has experienced a sustained period of intense pollution thanks to a sharp rise in its population. In the 1990s, satellite towns benefited from economic development and expanded in size and volume of activity, so that by the end of the decade the countryside was absorbed into the city, and urban zones surrounded factories.

It was during this period of upheaval that the Chinese capital set out its ambition to host the Olympics, ${ }^{(18)}$ and in 1998 unveiled a plan to check pollution in ten phases. ${ }^{(19)}$ Until 2000 , the authorities sought to replace domestic use of coal with natural gas, and promoted the use of coal with less sulphur content. Industries were moved well beyond the city limits and modernised to boost energy efficiency. ${ }^{(20)}$ This helped limit emissions of pollutants in general and $\mathrm{SO}_{2}$ in particular, despite rising coal use to meet the growing demand for electricity. It is worth noting, however, that while the predominance of gas and the rise in industrial productivity had a positive impact on the emission of pollutants, especially particulates, they were also responsible for a significant rise in emissions of $\mathrm{CO}_{2}$ and other greenhouse gases.

It was in 2000, when PMı was substituted for TSP as the measure, with the aim of reducing the annual average effect of sand storms, ${ }^{(21)}$ that the authorities strengthened the application of controls to curb particulate pollution. Firstly, construction sites dotting the burgeoning capital had to be covered in order to avoid the spread of dust, as did the vast sites for stocking materials (rubble, sand, coal) situated around the city. At the same time, many roads were paved and green barriers built. Although this led to a noticeable decrease in the larger particulates and their contribution to $\mathrm{PM}_{10}$, the reduction of finer particles needed further effort. So 85 percent of the ageing taxi fleet was replaced between
2004 and 2006, and two-stroke engined two-wheelers were prohibited, along with trucks during the daytime. The entry into force of European emission standards for vehicular traffic, Euro II, Euro III, and Euro IV, successively in 2003, 2005 , and 2007, ${ }^{(22)}$ led to the banishing of the most polluting vehicles to the city's outskirts. Despite these regulations, traffic pollution has grown to critical dimensions in these few years due to the city's inability to embrace public transport solutions and construct road infrastructure in line with escalating demand. The number of automobiles grew inexorably, even during the SARS epidemic of 2003, as many Beijingers avoided close contact with others in public transport. In 2000, half of the space on urban roads was occupied by private vehicles, company cars, and taxis transporting fewer than 10 percent of all passengers. The 90 percent travelling by bus occupied a mere 25 percent of urban road space.

After having turned a blind eye and perhaps even encouraged the explosive rise in car use, the authorities began attempting to counter the impact of what was becoming the main polluter in central Beijing. Public transport was developed and improved: from 2005 to 2008, subway lines increased from two to five. But the three-fold rise in network capacity is still insufficient, given the soaring demand. ${ }^{(23)}$ Fourteen lines in all are expected to be in operation by 2015 . Bus fleets have been modernised and now make up the largest number running on natural gas $(3,700)$. They run mostly within the Fifth Ring Road, and since 2008, two express bus lines for some satellite towns have doubled the total carrying capacity of the bus network.

The authorities tried out restrictions on automobile traffic in 2006 during the Sino-African summit, then in the summer of 2007 and during the Olympics (20 July-20 September, 2008). Of course, vehicular traffic's share of pollution is sig-

18. The 1990 Asian Games were seen by Beijing and the CPC as a rehearsal for a possible bid to host the 2000 Olympics. The candidature was decided in April 1991, and the Beijing Organising Committee for the Olympic Games of 2000 was formed.

19. Details of the plan in J.M. Hao and L. T. Wang, "Improving Urban Air Quality in China," J. Air \& Waste Manage. Assoc., No. 55, 2005, pp. 1298-1305.

20. In the process, Beijing drew on the experience of firms in the Pearl River Delta. In fact many years earlier, Hong Kong and Taiwan firms had exported pollution by relocating to the Pearl River Delta, where they could also take advantage of cheap labour and land. The energy efficiency of the factories there is still the lowest among production regions, and in terms of atmospheric pollution intensity, it is the country's worst performing region. Later, industries in the Yangtze delta and then the Beijing-Tianjin megacities made sure no production unit was moved without an improvement in energy efficiency.

21. This influence is considerable on the variations of TSP, as shown in Figure 2, where in 2003, for instance, the absence of sand storms led to a fall in TSP levels but not of PM10.

22. It should be noted that the Euro IV norm is in force in the European Union at present

23. Soon after lines 5 and 10 opened in 2008 , they became heavily crowded during peak hours, and that level has remained the same. 
Figure 2. Annual levels of TSP, PM10, SO2, NOx, NO2, number of vehicles and size of population between 1986 and 2007
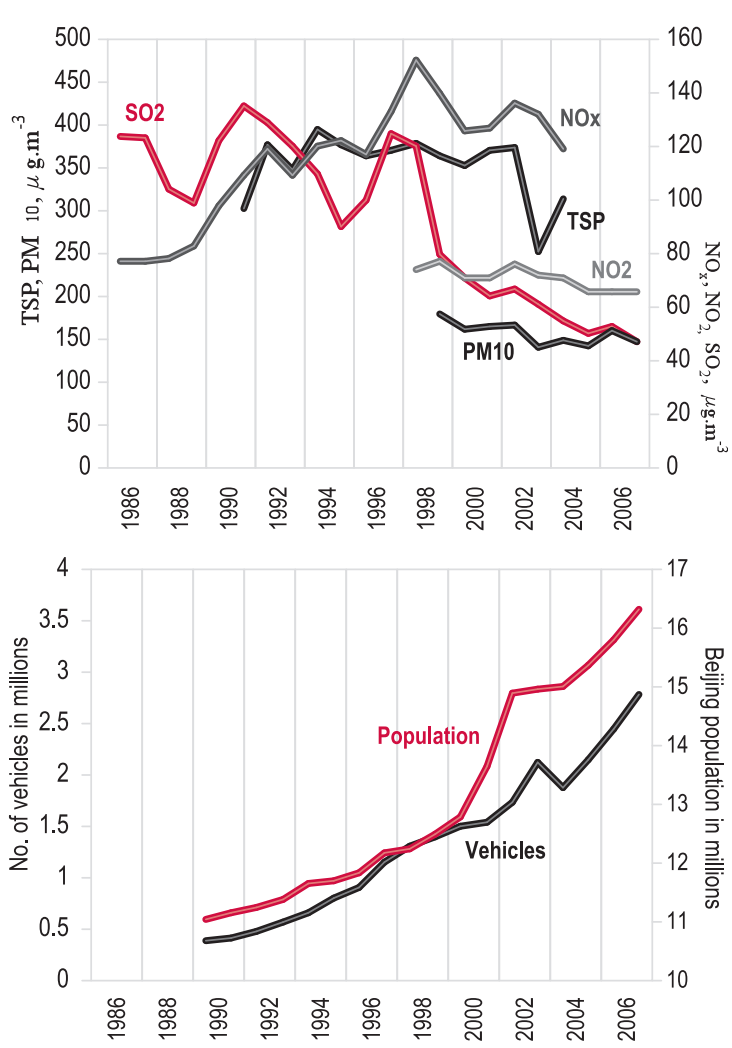

The pollution figures are taken from nine monitoring stations of the MEP.

Sources: $h$ ttp://www.bjepb.gov.cn/bjhb/portalo/default375.htm and $h$ ttp://www.bjstats.gov.cn/xwgb/tjgb/ndgb/

nificant (20-25 percent of particulate pollution, for example), but the direct influence of this source alone cannot be evaluated accurately, given the many meteorological factors at work such as the force and direction of wind. Nevertheless, pollutants from road traffic such as NOx decreased noticeably during this period, ${ }^{(24)}$ and the authorities retained the staggered traffic arrangement even after the Olympics. ${ }^{(25)}$

The Olympics was certainly a turning point in the history of air pollution in Beijing. The issue received exaggerated media coverage in the weeks and days preceding the start of the Games, but disappeared from view as a tolerable level of air quality was maintained for the duration of the event. Wind conditions often helped disperse pollutants (more than usual), and rains helped filter out particulates from the atmosphere. Even so, these good results were largely due to the thorough work carried out under pollution control plans starting in 1998.

The first consequence: these measures, along with steppedup international pressure during the Olympics, helped boost the authorities' management capacity. There is no doubt that the experience will be useful in future in defining new protection policies and putting in place more effective urban environmental management throughout the country.

The second consequence stemmed from controls implemented first at the municipal level, then in the Beijing urban zone, and later extended to five neighbouring provinces and municipalities: Hebei, Inner Mongolia, Shanxi, Tianjin, and Shandong. Given Beijing's geography, and in the absence of winds from the north or north-west to blow pollutants southward, it was necessary to curb not only local sources but also those in the region, up to 300 or $500 \mathrm{~km}$ from the capital. The challenge was to maintain the control efforts in central Beijing while gaining cooperation from the vast basin of Hebei and the north China plain, where 100 million people live and work. In this beehive of activity, observance and control mechanisms were tight enough to bring them in line with the capital, which had long been an island of modernity amid a sea of uncontrolled or under-controlled pollutants.

The third consequence was on the public perception of pollution issues, especially among the youth. Through years of the city's transformation in preparation for the Games, most Beijingers took pride in the International Olympic Committee's praise of the progress of building works as well as the high quality of the installations. The IOC's only reservations were about the state of the environment. Criticisms on this score reported by foreign media to a great extent helped raise consciousness of the environmental challenges facing the capital and its environs. Meanwhile, local NGOs and official initiatives such as the Beijing Public Net for Environmental Protection ${ }^{(26)}$ introduced several schemes in colleges to encourage individual or collective action for saving power and water, and for environmental protection. ${ }^{(27)}$

24. Wang Yuxuan et al, "Traffic restrictions associated with the Sino-African summit: Reduc tions of N0x detected from space," Geophys. Res. Let., No. 34, 2007, L08814, doi:10.1029/2007GL029326

25. Cars with licence plate numbers ending with 1 were barred from roads on Mondays, those with 2 on Tuesdays, etc. There were no restriction on weekends. All transgressions were punished with a 100 Yuan fine, which was rather light for motorists affluent enough to buy a car. Moreover, it is possible that some people bought a second car, as in Mexico in response to a similar traffic policy.

26. http://www.bjee.org.cn/cn/, site of the Beijing Municipal Publicity and Education Center for Environmental Protection, one of the departments of the EPB in Beijing.

27. Among the many rapid steps taken to sensitise Beijingers to environmental protection, it's worth noting the ban on supermarkets giving out plastic bags, which took effect on 1 July 2008 , only weeks after it was announced. 
With the Beijing Games out of the way, Shanghai's Expo 2010 is now in the sights, as well as the 16th Asian Games in November in Guangzhou that same year. Each megacity is adopting new means to better address the nature and dispersion of their pollutants, as well as their sources and the means of controlling them. Two major points with regard to air quality are under review:

First is the exhaustive listing of all atmospheric pollution sources, province by province, city by city, undertaken at the MEP's behest. ${ }^{(28)}$ Local authorities are charged with more accurately identifying priority sources for control. Centralisation of information crucial for predictions of air quality would also facilitate central government measures to adopt more relevant national aims for emission control.

The second point concerns the communication methods of officials dealing with atmospheric pollution. This weakness was glaring during the Beijing Olympics, when observers' attention was fixed on "blue sky" aims. A "blue sky" day is one in which the pollution index is lower than 100 (or $150 \mu \mathrm{g} / \mathrm{m}^{3}$ of $\mathrm{PM}_{10}$, which is four times the EU standard). Achieving targets of "blue sky" days became an obsession for the Beijing EPB. The number, fixed in 2008 at 255, ${ }^{(29)}$ has been rising year to year over the past 10 years in parallel with the share of the municipal budget allocated to environmental protection. It is undeniable that concrete steps have been taken regularly since 1998, but a glance through the figures on the EPB website ${ }^{(30)}$ reveals a possible adjustment of the values, which stand at just above 100. Some people have not hesitated to call this a fiddling of the figures. ${ }^{(31)}$ Over the last few years on average, the number of values just under 100 (96-100) was four times greater than the number of days slightly above 100 (101-105). These bizarre figures suggest that the values were often reduced by a few units in order to puff up the number of "blue sky" days. Such changes in the basic information, ${ }^{(32)}$ however minimal, give China's detractors a convenient stick with which to beat it. In order to emerge from this trap and speedily adopt tools and modes of communication, discussion groups of researchers and political decision-makers were set up by the most active EPBs with the MEP's blessings. Another sign of an evolution towards transparency in information was demonstrated recently through the AMFIC (Air Quality Monitoring and Forecasting in China), a joint EU-China initiative. The website in English and Chinese gives access to data on hourly and/or daily concentrations of the main atmospheric pollutants $\left(\mathrm{PM}_{10}\right.$, $\mathrm{NO}_{2}, \mathrm{SO}_{2}$, carbon monoxide, and ozone) in the big cities. ${ }^{(3)}$

\section{What does tomorrow hold?}

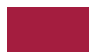

As seen earlier, scientific and technical management by environmental and industrial authorities, $R \& D$ units of laboratories, and modes of communication over pollution issues have been improving rapidly in dynamic urban zones and nearby areas under their direct influence. Meanwhile, the situation in middle-ranking cities remains suboptimal (even catastrophic in the smallest cities), and progress depends on the cooperation of local leaders. In order to achieve uniform progress, the MEP has undertaken a review of the mode of evaluating local officials that would be based not only on production figures and economic returns, but would also integrate their environmental performance as an indicator, following a method developed jointly by Yale and Columbia Universities in the United States. ${ }^{(34)}$

Finally, among the factors that can reshuffle China's economic cards, it is possible to envisage that a slowing of manufactured exports could affect the pollution level in the Pearl River Delta, where manufactured export goods accounted for 10 to 40 percent of $\mathrm{SO}_{2}$ and $\mathrm{PM}_{10}$ emissions. ${ }^{(35)}$ It will be interesting to watch the evolution of emissions, especially in the country's interior regions. As businesses move inward, attracted by fewer constraints than on the coast, these regions might well end up with new secondary activities thanks to a redefinition of the country's industrial priorities. $\bullet$

\section{- Translated by N. Jayaram}

28. http://www.gov.cn/zwgk/2006-10/23/content 420862.htm. The results will be submitted for the government's exclusive attention before the end of 2009.

29. Or $70 \%$ of the year; the objective was achieved a month before the 30 November 2008 target, and hailed by most newspapers in Beijing and the rest of China (http://www.chinanews.com.cn/gn/news/2008/11-30/1467988. shtml).

30. Beijing municipality website: http://www.bjepb.gov.cn. MEP site: http://datacenter.mep gov.cn/TestRunQian/ airdairy.jsp.

31. Steven Q. Andrews, "Inconsistencies in air quality metrics: 'Blue sky' days and PM10 concentrations in Beijing," Environmental Research Letters, No. 3, 2008, doi:10.1088/1748-9326/3/3/034009.

32. In fact, adjustments by a few units is negligible, in view of the uncertainties of the measurement (especially of PM10), which is of the order of 15 to $20 \%$. See: http://www.ambafrance-cn.org/spip.php?article4569.

33. http://www.amfic.eu/

34. The Center for Environmental Law \& Policy of Yale and Columbia Universities, through the Center for International Earth Science Information Network (CIESIN), has since 1998 been leading the development of national-level environmental indices. Its most recent publication, 2008 Environmental Performance Index (EPI 2008), gives national decision-makers an easy-to-use scientific tool to take account of environmental data in their work. The EPI 2008 classified 149 countries on their performance with regard to 25 indicators, which helps the countries to compare their management with that of neighbours and peers. However, $E P I$ only looks into environmental issues at the national level. Given China's geographic diversity and the local authorities' autonomy, a more efficient sub-index is being prepared.

35. David G. Streets, et. al., "Modeling study of air pollution due to the manufacture of export goods in China's Pearl River Delta," Environ. Sci. Technol., No. 40, 2006, pp. 2099-2107. 